\title{
PROLEGÓMENOS PARA APRENDER EL SURGIMIENTO DEL TRABAJO SOCIAL: TRANSFORMACIONES SOCIO-HISTÓRICAS EN FRANCIA (SIGLOS XVIII Y XIX)
}

\section{CONSIDERATIONS TO APPREHEND THE EMERGENCE OF SOCIAL WORK: SOCIO-HISTORICAL TRANSFORMATIONS IN FRANCE (XVIII AND XIX)}

Freddy Esquivel Corella ${ }^{1}$ freddy.esquivel@ucr.ac.cr

\begin{abstract}
Resumen
El estudio de los siglos XVIII y XIX en Francia arroja una serie de complejos socio-históricos determinantes en el análisis de la constitución del Trabajo Social, entre ellos se localizan la reorganización política, algunas formas incipientes de la reproducción capitalista, la renovación y fortalecimiento del Estado, el ímpetu de los movimientos sociales de clases, la instrumentalidad del saber y las mudanzas en el conocimiento social y la institución universitaria; todo ello entretejido con la configuración de una hegemonía burguesa que prevalece hasta la actualidad.

Palabras claves: Francia, Revolución Francesa, Trabajo Social, Estado.
\end{abstract}

\section{Abstract}

The study of theeighteenth and nineteenthcenturiesin France founda number of complexsocio-historical determinantsin the analysisof the constitutionof Social Work. These includea new social order, a basiccapitalist reproduction, the strengtheningof theState, the importanceof social movementsclass, theinstrumentalityof knowledgeand changes inthe modern university.

Keywords: France, French Revolution, Social Work, State.

Centro del feudalismo en la Edad Media y país modelo de la monarquía unitaria estamental desde el Renacimiento, Francia pulverizó al feudalismo en la gran revolución e instauró la dominación pura de la burguesía, bajo una forma clásica como ningún otro país de Europa. También, la lucha del proletariado cada vez más vigorosa contra la burguesía dominante reviste aquí una forma aguda, desconocida en otras partes (Engels, 1976).

1 Escuela de Trabajo Social, Sede Rodrigo Facio, Universidad de Costa Rica. 


\section{A forma de introducción}

El propósito de este ensayo es lograr un preámbulo a las transformaciones históricas derivadas de la historia francesa en los siglos XVIII y XIX que se entretejen con el surgir de la profesión de Trabajo Social.

Para tal fin, se recuperan algunos de los escenarios de esta nación, previo a la icónica Revolución Francesa; también, se abordan ciertos rasgos que se derivaron de las conquistas lideradas por la burguesía y su posterior hegemonía, al recurrir a un vigorizado y articulado Estado moderno. Junto a lo anterior, se delinean definidos perfiles de la base intelectual y universitaria que caracterizaron este período, para reflexionar en cada subapartado sobre el entretejido que esos elementos generan en la naturaleza de la profesión citada.

La profesión de Trabajo Social se configuró socio-históricamente en tanto las transformaciones revolucionarias burguesas propulsaron las condiciones para su surgimiento en el marco de las tensiones y movimientos de fuerzas que se atisban en la Europa del siglo XVIII y XIX.

Francia es uno de los terrenos relevantes para abordar ese entretejido de relaciones, donde, si bien es cierto, esta categoría profesional adoleció incipientemente de un desarrollo formal académico y gremial emblemático como en otras partes del orbe (ver por ejemplo obras de Martinelli,1997; Manrique,1982; Iamamoto y Carvalho,1984; Montaño,1995; Torres,1987, Bouquet, 2004; De Robertis, 2004 y Beau, 1980), lo acontecido en la república gala definiría la concatenación con los planteamientos de la Modernidad, el Estado capitalista, las luchas sociales clasistas y el conocimiento explicativo predominante orientado por los análisis iusnaturalistas y conservadores que han tenido significativo arraigo en el campo en cuestión.

El detonante de este impulso histórico fue la revolución burguesa, la cual conlleva a una transformación europea inspirada en el Renacentismo, la Ilustración, el pensamiento liberal (Droz, 1974), y, desde luego, los gérmenes del socialismo utópico y el positivismo como referencias explicativas predominantes para argumentar las dilucidaciones y estudio de las relaciones de clases (ver por ejemplo las distintas obras de Saint-Simón en Durán, 2008, Comte en Muglione, 1996 y Durkheim en Monereo, 2008), en el filo de las agites que dan soporte a las dialécticas francesas.

Como será analizado, las conquistas galeses incitaron a su vez la avanzada de la modernidad, entendida, según Sánchez (1999), como el proceso que se abre con el proyecto ilustrado burgués de emancipación humana.

La modernidad planteó cuestiones cruciales que no serían interrogadas con más impulso hasta finales del XVIII e inicios del XIX; por ejemplo, las críticas a la obra de fisiócratas franceses por parte de las leyes del mercado inglés, así como el desarrollo de la economía burguesa, en la cual el trabajo humano adquirió un significado distinto en la producción y acumulación de la riqueza y de las relaciones sociales de clases (Hobsbawn, 1964).

Por su parte, la ruptura con un modo de vida feudal, así como la instauración de un orden que prometía libertad, justicia, resistencia a la opresión, igualdad y trabajo (Declaración de los Derechos del Hombre y el Ciudadano, 1789), fue catalizadora de nuevas determinantes como las nociones de ciudadanía y "cuestión social" que tanto eco tienen en el campo del Trabajo Social.

Sumado a ello se constituye la demanda de intervención pública y privada en asuntos de derechos sociales, refractándose en el trence entre burguesía, sociedad civil, iglesias (en especial católica y protestante) y Estado.

Lo anterior exigió la preparación y dirección de determinados(as) agentes que debían hacer frente al pauperismo, la expoliación y la miseria en un país que para fines del siglo XVIII cobijaba alrededor de 26 millones de habitantes, el cual declaró su condición de República el 22 de setiembre de 1792 (Ford, 1973).

Este momento de la historia europea posibilitó condiciones para la ruptura con las tradicionales sociedades feudales (Ancien Régime), así como un avance en las relaciones que se iniciaron bajo el liderazgo burgués (Netto, 1992), y que dejarían su impronta en el desarrollo orgánico del Trabajo Social en occidente.

Dicha profesión halla en esos elementos primigenios, bases determinantes de su 
compleja naturaleza, así como de los movimientos de fuerzas que la materializan en la historia y sin los cuales es inacabada su ineluctable aprehensión coetánea.

\section{Algunas de las condiciones que desembocaron en la Francia revolucionaria}

Francia se había caracterizado por ser una nación con un elevado número de habitantes al superar de manera importante el promedio demográfico europeo (Lefebvre, 1960); aunado a ello, en el siglo XVIII, la población rural representaba el $85 \%$ del total. Además:

A partir de 1730-1750 se inició un largo periodo de crecimiento económico, que si bien no introdujo grandes innovaciones tecnológicas, preludiaba el cambio a experimentar la economía en los siglos XIX y XX. El crecimiento de la población, el alza de los precios y el desarrollo del comercio interior, gracias a las mejoras de las comunicaciones y a la mayor disponibilidad y rapidez de dinero, fueron los principales motores del cambio. [...] Esto hizo del siglo XVIII el comienzo de una nueva época (h.1730-h.1840) de lenta y discontinua transición a la sociedad industrial. [...] El desarrollo de Francia durante el siglo XVIII fue muy importante y convirtió al país en una de las principales potencias económicas. La tasa de crecimiento de las manufacturas, alrededor de un $1,9 \%$ anual, probablemente era superior a la de Gran Bretaña (alrededor del 1,2\%). Si bien la tecnología británica era desde tiempo atrás más avanzada, sólo durante el período de la Revolución y el Imperio se hizo notoria la divergencia. Francia, forzada por imperativos técnicos [...] habría de contentarse con seguir sus pasos a lo largo de buena parte del siglo siguiente (Price, 1998:33 y 35).

Por su lado, las relaciones internacionales de Francia también abonaron a la situación que erosionó su estabilidad económica, prueba de ello fueron las altas inversiones desarrolladas por Luis XVI para apoyar la independencia de las colonias en los Estados Unidos, en tanto una estrategia que minimizaría el poderío de Inglaterra (Hobsbawn, 1964).

Lefebvre (1960) afirma que después de la Guerra de Siete años (1756-1763) (impelida en gran medida por las rivalidades entre Inglaterra y Francia en razón del dominio de suelos en el norte de América), la economía francesa había conocido algunos tiempos prósperos y amplió su intercambio mercantil y sus productos manufacturados. Relacionado con ello, se cita lo siguiente, según Duby y Mandrou (1981): “La prosperidad francesa - y europea, sin duda- del siglo XVIII se prolongó hasta alrededor de 1775 , fecha en la cual, sin retornar a los horrores de otros tiempos, poco a poco olvidados, se inició una crisis de la economía francesa que se prolongó hasta los primeros años de la Revolución, por lo menos hasta 1790 (...)".

Sumado a ello, la situación se agravó debido a una marcada ausencia de pago de los impuestos a raíz de las malas cosechas; por su lado, se denotó un aumento poblacional significativo, que por la misma carencia de alimentos, provocó presión social en las urbes excitada por la llegada de emigrantes rurales en busca de trabajo; el resultado fue un París hambriento (Bloch, 1995 y Petit, 1997).

Dentro de las cargas que soportaban los campesinos, se cita la erogación de gravámenes tales como el diezmo a la Iglesia, a la sal y al vino. Sumado a ello, los salarios en las zonas urbanas no aumentaban, y el precio de los granos básicos remontó en un 60\% entre 1730 y 1789 (Ford, 1973). A su vez en este período:

[...] cayó la demanda en la construcción, el sector textil y respecto a los demás productos de numerosos talleres rurales y urbanos. [...] El empleo y los salarios de buena parte de la población se derrumbaron en el mismo momento en que crecía de manera sustancial el coste de la vida. [...] gentes que morían de hambre o se veían forzadas a comer alimentos en estado de putrefacción, hierbas y hierbajos. Los mendigos eran omnipresentes [...] Los delitos se multiplicaban (Price, 1998:89).

Ante tal crisis fiscal, la monarquía francesa se propuso por lo tanto establecer un impuesto a las propiedades, lo cual tuvo reacciones adversas por parte de ciertas clases; entre ellas, algunas fracciones del clero, la nobleza (distinguida por su familia de nacimiento), la clase media, los profesionales y la aristocracia (Lefebvre, 1960).

Por su lado, la burguesía había logrado acaudalar una importante riqueza provocada por su participación como mercaderes e intermediarios en el comercio marítimo, al aprovechar también el remanente de capital para invertirlo en operaciones financieras, comprar títulos de la nobleza, conseguir ponerles precio a puestos 
administrativos en el gobierno o los municipios; incluso dio empréstitos al Estado para enfrentar algunas de sus deudas extranjeras (Rudé, 1974).

En ese crítico contexto, la industria francesa era incipiente, aunque se perfilaban algunos avances que luego se impulsaron por logros de la Revolución Industrial (1780 a 1830 aproximadamente) a pesar de que la inversión fabril no se constituía en un campo determinante de dicha economía para esa época (Duby y Mandrou, 1981).

Otra de las condiciones que llevaron a la movilización social fue la presión de la prensa, la cual influyó en la difusión de ideas de la Ilustración, a pesar del alfabetismo francés que superaba la media europea (Hobsbawn, 1964).

Junto a ello es importante destacar el aparecimiento del Tercer Estado, conformado por algunos profesionales parisienses, funcionarios públicos, negociantes y sectores proletarios, el cual era liderado especialmente por la burguesía (guiado bajo el lema: la burguesía no tiene rey, la verdadera forma de su dominación es la república, Marx, 1976).

Relacionado con ello se puede citar lo siguiente, según Droz (1974): "En Francia fue donde la ascensión de la burguesía revistió un carácter más espectacular. Aquí es donde se definió más claramente, en oposición a la nobleza, a la que le arrebató el poder en la revolución de 1830 , y al «pueblo» del que se siente separada por sus ocupaciones y su forma de vida".

Por tanto, las condiciones sociales en que se reproducía la mayor población de Francia, así como las presiones que ejercían las clases hegemónicas, condujeron a la articulación y entreteje de intereses y agendas políticas que detonaron en una lucha social y transformaron la organización existente y robustecieron las alteraciones productivas y reproductivas que se localizaban en el viejo continente.

La modernidad burguesa fue el basamento más significativo que irrumpe en esta nueva apuesta que desatan dichos avances, al conducir a una emancipación bifurcada en una legalidad política relevante, pero en una imposibilidad material de lograr enrumbar en iguales condiciones -ciudadanía- de las que tenía la burguesía a los sectores que se habían aglutinado en el Tercer Estado.
Además, las discusiones en materia de ciudadanía moderna se conjugan en Francia en un marco realmente polémico e interesante, en letras de Lukács (2003): "Se defiende una libertad y una igualdad que, en realidad, existen de forma sumamente problemática (...) La Revolución Francesa vivía en la tensión entre ciudadano y burgués (...)".

\section{Sin embargo:}

[...] esta bourgeoisie no era una «clase media» homogénea. No era aceptada por la aristocracia, nacida para la judicatura, y también se encontraba separada de la inmensa mayoría del pueblo por razones de riqueza o de posición profesional y por un gran sentido de su propia importancia que a sus ojos la elevaba por encima del pueblo llano. Como grupo privilegiado era tan proclive a las diferencias sociales dentro de sí como a las que separaban a los de «abajo». La bourgeoisie rica derivaba su posición de la tierra, las finanzas o la industria, e incluía también en sus filas a los hombres que habían alcanzado la cumbre de las profesiones y posiciones dirigentes en el servicio del Estado. Este grupo conservaba celosamente su identidad y su poder político frente a la bourgeoisie «media» de los profesionales menos prósperos y distinguidos y la petitebourgeoisie, que estaban excluidas del derecho al voto (Grenville, 1980:27).

\section{Ampliando lo anterior se distingue:}

La burguesía no era homogénea. En primera fila estaban los financieros, cuyo papel había crecido al servicio del Estado. Los Receptores generales, a los que éste encargaba de percibir los impuestos directos, los banqueros que alimentaban la Tesorería, los municioneros que proveían al ejército y la marina. Junto con la finanza, el comercio marítimo ofrecía el principal medio de hacer fortuna. Pero los negociantes no estaban rigurosamente especializados: podía vérseles simultáneamente como armadores ,banqueros y manufactureros. La industria no tenía el predominio en la economía; la concentración de las empresas apenas empezaba y el capitalismo conservaba su forma comercial. [...] La condición de los burgueses era pues muy variada. Los financieros y los negociantes tenían sus residencias en las grandes ciudades y alternaban con la nobleza. En provincia, el burgués conservaba mucho de su origen campesino; era ahorrativo y su mujer ignoraba la moda; las distracciones eran poco frecuentes; la autoridad del marido y del padre seguían siendo absolutas. Entre el burgués y el hombre del pueblo las relaciones eran frecuentes (Lefebvre, 1960:32 y 34).

Sumado a ello, se resalta que la llegada de la hegemonía burguesa, rompía con la tradición nobiliaria del pasado medieval en el que la tierra era la única riqueza y sus poseedores (la nobleza) eran los amos de los que la cultivaban; 
de tal manera, el comercio y la industria se configuraban en centros de producción y circulación de mercancías que trascenderían esa forma de acumular peculio desde el feudalismo (Lefebvre, 1960).

Así las cosas, las revoluciones de la era moderna se intensificaron en estos siglos XVIII y XIX y los movimientos del poder se realinearon en un contexto posrevolucionario al confrontar, esta vez, a otras dos clases que se gestaban de forma antagónica: la burguesía y el proletariado; esta última tuvo que dar la cara ante crudas condiciones de existencia que derivaron de la avanzada del capitalismo y la sociabilidad burguesa, las cuales impactarían en su sobrevivencia en un nuevo capítulo de la historia moderna.

Lo expuesto hasta el momento permite recuperar el valor de este contexto prerevolucionario para el análisis de la génesis del Trabajo Social; en tanto, en este escenario, se localiza una base germinal que le dará un empuje trascendental en su naturaleza.

Por un lado, se articula con un giro determinante que va a marcar la historia; tal como lo son los movimientos sociales clasistas, la alteración de un orden social y la acción revolucionaria como mecanismo de transformación humana, ya que:

Este modo de producción no debe considerarse solamente en el sentido de la reproducción de la existencia física de los individuos. Es ya, más bien, un determinado modo de la actividad de estos individuos, un determinado modo de manifestar su vida, un determinado modo de vida de los mismos. Los individuos son tal y como manifiestan su vida. Lo que son coincide, por consiguiente, con su producción, tanto con lo que producen como con el modo de cómo producen. Lo que los individuos son depende, por tanto, de las condiciones materiales de su producción (Marx y Engels, 1976:16).

El Trabajo Social entraría a ser parte de las categorías derivadas de este nuevo modo de existencia al tener como escenario privilegiado la vida cotidiana del ser social, las condiciones materiales de manifestar su sobrevivencia y su reproducción subjetiva (Netto y Falcão, 1987).

Asimismo, esta profesión encuentra una plataforma para su desarrollo que deriva en una emancipación, fundamentalmente política, que avanza en la sociabilidad y la socialización; de igual modo, se imbrica con categorías tan determinantes como el trabajo libre y asalariado, la propiedad privada, la acumulación de medios de producción, las nuevas reglas de explotación, producción y consumo, así como un corolario de derechos que en definitiva fracturan las formas anteriores de organización humana como lo fue el esclavismo y el feudalismo.

De tal manera, esas mediaciones constituyentes de la sociedad burguesa se fusionarían como parte de los ejes que emplazarían al Trabajo Social con la realidad, instrumentalizándola prioritariamente en razón de los intereses de las clases hegemónicas y el Estado (Netto y Braz, 2006).

\section{La Francia posrevolucionaria burguesa}

La revolución burguesa que tomó cuerpo en suelo francés, básicamente rompió con cierta libertad política que le permitió mantener en pie sus intereses; justamente, la emancipación social (Lukács, 2003) (en su sentido ontológico) quedó pendiente; esta condición subsumió el pleno albedrío humano a la liberación de la explotación del trabajo que caracterizó al feudalismo tal y como quedó signado en la Constitución de 1791, específicamente en su preámbulo:

La Asamblea Nacional, queriendo establecer la Constitución francesa sobre los principios que acaba de reconocer y declarar, decreta la abolición irrevocable de las instituciones que vulneraban la libertad y la igualdad de derechos. -Ya no hay nobleza, ni pares, ni distinciones hereditarias, ni distinciones de órdenes, ni régimen feudal, ni justicias patrimoniales, ni ninguno de los títulos, denominaciones y prerrogativas que derivaban de ellas, ni órdenes de caballería, ni ninguna de las corporaciones o condecoraciones para las cuales se exigían pruebas de nobleza o suponían distinciones de nacimiento; ya no existe más superioridad que la de los funcionarios públicos en el ejercicio de sus funciones. -Ya no hay venalidad, ni adquisición por herencia de ningún oficio público. -Ya no hay, para ninguna parte de la Nación, ni para ningún individuo, privilegio o excepción alguna al derecho común de todos los franceses. -Ya no hay gremios, ni corporaciones de profesiones, artes y oficios. - La ley ya no reconoce ni los votos religiosos, ni ningún otro compromiso que sea contrario a los derechos naturales o a la Constitución (p. 1)

Con este talante, se reconfiguró una nueva escena de expoliación, miseria y pauperismo de aquellas clases que no ostentaban el poder político y material concentrado por la burguesía, y que reacomodaba las condiciones consecuentes 
de las luchas sociales venideras, las cuales se instauraron en el capitalismo bajo la nomenclatura de revolución proletaria, la cual se asomó paulatinamente en ese contexto un poco antes de la mitad del siglo XIX, y transformó en pleno las relaciones sociales.

A su vez, fue evidente que con las conquistas contra el sistema señorial francés, se erosionaron los derechos de los feudales sobre los campesinos(as), así como las diferencias entre nobles y plebeyos(as) en cuestiones de impuestos y castigos judiciales; por ejemplo, los tribunales notables que daban trato diferenciado a las clases dominantes se desmoronaron; sin embargo:

La pobreza siguió siendo endémica. Los planes oficiales para que humildes sansculottes y campesinos pobres participasen en la distribución de las tierras confiscadas a los emigrados aristócratas no alteraron significativamente la situación [...] ciudadanos ya prósperos se engulleron la nuevamente disponible propiedad. A esta fuente de resentimiento por parte de la clase más baja se unían la creciente inflación [...] y nuevas y severas penurias alimenticias, cuyo origen estaba en una desigual distribución, empeorada por las requisas militares en algunas zonas [...] (Ford, 1973:134).

Fueron notorias las erosiones regionales en impuestos, como en la propiedad de empleos públicos en tanto posesión privada; por otro lado, las restricciones que colocaban los gremios para ejercer un oficio o artesanía fueron superadas por las nuevas configuraciones del mundo del trabajo, incluso la Carta Magna de 1791 aclamó que todos los ciudadanos son admisibles en los puestos y empleos, sin más distinción que la de las virtudes y los talentos.

El hambre, según Ford (1973), continuaba azotando a los grupos más miserables, lo que significó que la administración pública tuviese que crear un ordenamiento territorial particular y localizado en departamentos, distritos, cantones y comunas; en ese marco, se erigieron órganos particulares; tales como el Tribunal Revolucionario, el Comité de Seguridad General y el Comité de Salud Pública con el fin de atender a las poblaciones más pauperizadas de los centros urbanos.

Además, es posible agregar que:

[...] los «costes de la Revolución» fueron elevados y que, pese al gran sufrimiento, se consiguió poco en cuanto a la modernización de las estructuras socioeconómicas, [...] sin embargo, los méritos de la creación de una nueva cultura y el establecimiento de nuevas instituciones centradas en la idea de los derechos del hombre [...] alterarían profunda y positivamente la manera de concebir las relaciones sociales. [...] La abolición de los gremios, la prohibición de asociaciones de trabajadores y la desaparición de las barreras aduaneras internas sentaron las bases de la libertad económica. Muchos hacendados y campesinos se beneficiaron de la desaparición del diezmo y de los derechos señoriales (Price, 1998:104 y 131).

La precariedad de la economía francesa se descolló con profundidad en 1810, año cuando las cosechas eran paupérrimas y se hundió el limitado desarrollo industrial alcanzado; además, los controles sobre los trabajadores eran cada vez más rígidas; en relación con eso se puntualiza:

A partir de 1803 se le exigió a todo trabajador estar en posesión de una libreta de trabajo, para presentarla a su empresario al entrar en un nuevo empleo. Dicho documento identificaba a su tenedor con fines políticos y mostraba las condiciones en que había dejado su anterior trabajo. El no estar en posesión de la libreta de trabajo era considerado como prueba de vagabundeo voluntario. A despecho del prometedor advenimiento de juntas locales de arbitraje y la existencia de ciertas hermandades de trabajadores (los campagnonnages, tolerados por el régimen para limitados fines sociales, pero mantenidos bajo estrecha vigilancia policial) los trabajadores franceses permanecían esencialmente aislados a merced de sus empresarios y del Estado (Ford, 1973:191).

En el período de gobierno de los Borbones (Luis XVIII y Carlos X), luego de la derrota de Napoleón I, las fracciones trabajadoras se movilizaron para lograr mejores salarios, reducción de la jornada de trabajo y prohibición de maquinaria que sustituyera la fuerza humana.

Interconectado con ello, es evidente que la sociedad francesa de mediados del siglo XIX se encuentra ante una de las polémicas más relevantes, hasta 1830 se había hablado de miseria obrera (Guy, 1997), pero conforme se penetra la lógica de la acumulación del capital y la explotación del trabajo, el escenario es inédito:

Globalmente se enriquece; tanto el valor de la producción agrícola como, sobre todo, el de la producción industrial se eleva. Y sin embargo, la mayoría de la población se empobrece: los salarios bajan y en determinados momentos se hunden literalmente [...] Ciertamente, el antagonismo entre pobres y ricos no es ninguna novedad, sino que ha sido el tema de infinidad de proclamas y exhortaciones a través de los siglos. Pero, por primera vez, se va a plantear la cuestión en el terreno industrial; por primera vez se va a plantear el problema de 
la máquina y el hombre, de las riquezas materiales en rápida expansión y de unos ingresos obreros en acelerado decrecimiento [...] la miseria crece paralelamente a la concentración capitalista [...] se trata de un empobrecimiento de un carácter completamente nuevo, sin relación alguna con los períodos precedentes [...] (Lefebvre, 1960:63 y 64).

Sobre este punto, cabe también citar lo siguiente:

En el siglo XIX, la pobreza, la miseria y las condiciones de vida bastante duras de la clase obrera engendraron diversos conflictos, llegando a una crisis social y política que se llamó "la cuestión social". Junto con las obras caritativas y las asociaciones filantrópicas que trataban de mejorar la situación a través de una reconciliación de clases, el Estado se preocupaba del tratamiento social de la cuestión social y se transformaba en un Estado legislador [...] (Bouquet, 2004:221 y 222).

Conexo a ese particular, es meritorio resaltar que la madurez de las fuerzas sociales proletarias, que se vieron desbancadas por el abandono de las luchas alcanzadas por la burguesía, estimularon la importante y "aniquilada" gesta prerevolucionaria de las Comunas de Junio de 1848, provocada por las pésimas cosechas de 1845 y 1846 , la llamada plaga de la patata y la crisis general del comercio europeo, lo que conllevó a sangrientos enfrentamientos entre Estado y proletariado, provocada por el ímpetu capitalista (Marx, 1976).

$\mathrm{Al}$ respecto se destaca:

La historia de la revolución en Francia en 1848 ilustra la distinción entre la lucha por el poder de unas élites dominantes enfrentadas (que llevó en primer lugar a la revolución) y el intento de llevar a cabo cambios en la sociedad y en el destino del hombre de la calle que llevaría al baño de sangre de junio. [...] Los pobres de París, los artesanos sin empleo y los obreros en sus numerosos pequeños lugares de trabajo [...] intentaron conseguir mejores condiciones de vida mediante un cambio político [...] (Grenville, 1980:25).

A pesar de esas luchas metropolitanas, en la Francia rural los campesinos seguían dependiendo de la nobleza y del grupo privilegiado conocido colectivamente como Notables (un conjunto de representantes políticos locales que acaudalaron riqueza y autoridad en las nuevas estructuras organizativas y toma de decisión de la sociedad burguesa, Price, 1998); a su vez, en los entretelones de las artimañas de Napoleón II, se redujo el voto universal con el fin de tener mayor maniobra sobre un selecto grupo de electores; por ejemplo para sufragar, aparte de contar con algún capital, se exigió una estabilidad laboral de al menos tres años; sin embargo, las personas que vagaban tratando de lograr vender su fuerza de trabajo no evidenciaron ese requerimiento de residencia permanente que se les imponía; eran excluidos a su vez quienes habían sido procesados por la justicia como fue el caso de los "comuneros" de París; al respecto se cita:

En algunos departamentos y sobre todo en regiones industriales y urbanas por lo menos la mitad del electorado se vio privada del derecho al voto. Se ha calculado que el electorado se vio reducido de nueve millones y medio a seis millones. Para asegurarse de la exclusión de la izquierda militante, la ley electoral, además privó de ese derecho a todos aquellos que hubieran sido declarados culpables por los tribunales (Grenville, 1980:139).

Por otra parte Droz (1974) rubrica que la evolución capitalista posterior a la Revolución se produce en Francia con claro retraso si se le compara con Inglaterra, ya que su avanzada es más pausada y de menor envergadura; además, refiere textualmente:

[...] todavía en 1848, el 75 por 100 de la población se dedica a la agricultura [...] En cuanto a la industria, ésta se ve sometida a un régimen de protección arancelaria, e incluso de prohibición de las importaciones, que constituye la causa fundamental del retraso de la industria nacional [...] las máquinas se difunden, pero más rápidamente en el hilado que en el tejido [...] el sector textil sigue estando estrechamente sometido a los métodos del capitalismo comercial, bajo el control de fabricantes-comerciantes. Por el contrario se puede constatar la decadencia significativa de la industria doméstica y rural [...] En resumen, aunque en la Francia de mediados del siglo XIX todavía dominan la pequeña tienda y el taller, y las grandes empresas constituyen la excepción, lentamente se va formando un capitalismo de «monopolio», favorecido por el gobierno (Droz, 1974:25).

Duby y Madrou (1981), por su lado, asienten que es hasta 1815 y 1830 que se pudieron palpar en este país algunos limitados impulsos de los avances de la Revolución Industrial; empero, hasta la mitad del siglo XIX, se da la llegada de la máquina de vapor; mientras tanto, el campo de los tejidos y la construcción eran los principales pilares de la actividad capitalista; para 1896, el 
60,9\% de los habitantes vivía de ocupaciones agrarias (Mommsen, 1971 y Price, 1998).

Quizás una de las condicionantes para el retraso de la sintonía de Francia con el avance de las fuerzas productivas de Europa fue la inestabilidad política que le caracterizó, incidiendo, tal y como se leerá en el siguiente subapartado, en las orientaciones del Estado moderno.

El desarrollo a posteriori de la Revolución Francesa también ensanchó la modernización estatal que estimulaba una nueva organización política y de producción, al alterar, innovar y renovar la división social, técnica e intelectual del trabajo (Grenville, 1980).

En las primeras décadas de siglo XIX todavía predominaban las formas rudimentarias de producción; posteriormente, se desarrolló la manufactura pesada, especialmente la ingeniería y las industrias químicas en el norte y este de París; mientras en las áreas centrales convivían trabajos artesanales con un paulatino aparecimiento de actividades administrativas, financieras y comerciales. Las alteraciones en la vida de la clase trabajadora fue también relevante, la inmigración a las ciudades generó concentraciones en barrios periféricos, aumentando a su vez la demanda de mano de obra para la industria, el cual se mostraba más atractivo por la paga, el tiempo libre regulado y algunas garantías sindicales que eran prácticamente inexistentes en el campo rural.

La organización sindical al finalizar el siglo XIX no era despreciable; para 1890 se localizaban mil sindicatos, tanta fragmentación era producto de la forma en que se regulaba y controlaba el trabajo a lo largo del país, circunscrita por regiones autónomas (Bourses de Travail); ya en 1895 se contabilizaban 419.000 obreros en 2.163 comités de trabajadores (más adelante, esfuerzos articuladores desembocan en la Fédération des syndicats et groupescorporatifs -1886, Fédération des Bourses de Travail -1892 y la Conféderation Générale du Travail -1895) (Wolfgang, 1971).

Sin equívoco, una de las consideraciones más determinantes para el Trabajo Social que emergen del contexto analizado en este acápite del artículo, es el lograr aquilatar la relevancia de los movimientos revolucionarios en el desarrollo de la historia; si bien son oscilaciones de fuerzas que se confrontan con muchas imperfecciones, permiten evidenciar las posibilidades de avanzar (o regresar) a estamentos de organización social que al parecer únicamente se materializan al trastocar de raíz, las bases institucionales que sustentan un determinado modo de vida.

Otra mediación relevante, se devela al comprender que una clase que otrora liderara una gesta revolucionaria puede prolongar un conservadurismo y acciones regresivas, que perpetúen confrontaciones latentes e históricas, como se evidencia hasta el siglo XXI. Por tanto, los análisis clasistas son indispensables en la recuperación de la totalidad de la sociedad; sin embargo, ellos no agotan la máxima explicación de las relaciones sociales en ningún período, pero son su nodo vital.

Los resultados de la gesta revolucionaria del siglo XVIII derivaron en la confrontación de dos clases inéditas (capitalistas burgueses y proletariado); de tal forma, el Trabajo Social, como cualquier otra categoría que emerge o fuera rearticulada en este contexto, se reproduce en esas confrontaciones, matizada por distintas complejidades y mediaciones que la singularizan.

Para el campo profesional en estudio, se le plantean una serie de demandas que ningún agente social había tenido que resolver en la historia, en tanto esta sociedad es la primera que avanza sobre patrones en los cuales se evoca políticamente un orden social diferenciado de una manera distintiva al esclavista o el feudal (incluso bajo argumentos de igualdad, fraternidad y libertad), pero que a su vez, trasmuta esas promesas modernistas y las instrumentaliza para el asentamiento y prolongación de una hegemonía asociada a una clase que liderará un nuevo ordenamiento y modo de producción y que intensificará las contradicciones que encallaron a la humanidad hasta este borde de la historia.

No existía anteriormente una sociedad como esta, tampoco las consecuencias que se palpan de dicha realidad; ante ello, el Trabajo Social no es posible de analizar bajo continuidades de otros ordenamientos de vida previos; lo anterior no significa un borrón y cuenta nueva para la humanidad, pero sí una gesta revolucionaria que consume, agota, crea y reconstruye el patrimonio que hasta el momento se había conquistado en este momento de síntesis. 


\section{El Estado moderno y sus condicionantes}

Sin duda, una de las alteraciones más significativas que subyacen en este contexto de estudio y de importancia para el Trabajo Social son las transfiguraciones (con fracturas y continuidades definidas por una clara orientación política clasista) que se evidencian en el Estado, en tanto su principal empleador en muchos países (Tello, 2000).

El Estado en Francia desde la era de Luis VI permanecía estacionario (Lefebvre, 1960), la ausencia de una organicidad, cita el autor, provocaba diferencias entre las circunscripciones administrativas, judiciales y financieras que se matizaban por la desigualdad.

Producto de las luchas históricas antes reseñadas, y con el debilitamiento de las fuerzas que respaldaban el feudalismo, tales como la monarquía, la nobleza, la aristocracia y las iglesias, se presionó a este órgano para tener un mayor repunte de la ciencia, el arte, la literatura, la política, la justicia y la economía mercantil.

La figura del Estado fue apareciendo como un ente más vinculado a innovadores determinantes históricos en razón de que, según Price (1998): "Además de la libertad que proclamaba la Declaración de Derechos de 1789, su preámbulo garantizaba los derechos de asistencia pública, educación e incluso insurrección contra la opresión".

Por tanto, es posible asentir, siguiendo a Ford (1973), que la Revolución Francesa decantó en una boyante expresión de nuevos y radicales puntos de vista concernientes al Estado, el individuo y las pretensiones de ambos.

El marco constitucional que se demandaba en este contexto derivó en una Carta Magna en 1791, la cual literalmente señaló en su Título Primero la creación y organización de un socorro público para criar a los niños abandonados, atender a los pobres inválidos y proporcionar trabajo a los menesterosos que siendo capaces no hubiesen podido procurárselo.

Una de las representaciones más maduras de estos acomodamientos se consolidan en el imperio representado por Napoleón I, el cual impulsó una serie de cambios en la administración pública, el derecho y la educación en su llamado Código Napoleónico, promulgado en 1804 y compuesto por 2.281 artículos que retoman bases del Derecho Romano, léase:

Era una estructura legal concebida para promover el orden y la estabilidad de las relaciones interpersonales, una razonablemente pronta acción de los tribunales, la uniformidad nacional en tanto que opuesta a las abigarradas costumbres religiosas, la igualdad civil, la libertad religiosa y, naturalmente, el poder del Estado. En el procedimiento criminal se reintrodujo la tortura sobre una base limitada [...] El Código en su conjunto era un esfuerzo intelectualmente respetable para conciliar las leyes del Antiguo Régimen con las de la Revolución, pero también era un poderoso instrumento de gobierno autoritario (Ford, 1973:189 y 188).

Se puede afirmar que ese Código esbozó la arquitectura estructural del Estado burgués que luego se ratifica en su consolidación europea, y sus modos de enfrentarse a las exigencias de reorganización capitalista que calaron en otros territorios (Rudé, 1974). Articulado a ello, se puede acentuar:

A continuación se adoptaron otras disposiciones que tenían por objeto la consecución de una administración más eficaz y representan un nuevo paso en pro de la creación de un Estado centralizado, l'Etatbureaucratique. [...] intentaba proteger y regular la transmisión de la propiedad privada que, tras la desaparición de los estamentos, era el origen de la posición social [...] Se creó una nueva jerarquía basada no sólo en la riqueza, sino también en el servicio al Estado. Sus miembros reclutados entre las clases medias y altas, se educaron en los lycées [...] bajo estrecha supervisión estatal. [...] el 20\% procedía de las clases populares y el $58 \%$ de la burguesía [...] En una sociedad eminentemente agrícola, en la que la riqueza derivaba en lo esencial de la tierra y era indispensable para mantener el adecuado estilo de vida y proporcionar la educación que permitiese el acceso a la actividad profesional o a los cargos políticos, [...] Los años posteriores a 1789 facilitaron la movilidad social, sobre todo mediante el servicio al Estado [...] las aspiraciones de los nuevos ricos se acomodaron al modelo que habían definido los que ya estaban establecidos. Las élites sociales de comienzos del siglo XIX, como las del XVIII, eran el resultado de un complejo proceso de mestizaje entre familias bien asentadas y aquellas con ambiciones. (Price, 1998:123,132 y 215).

Junto a ello, las fracciones dirigentes del Estado debieron ingeniar la creación y asignación de puestos públicos (y por ende técnicos y profesionales), las normas y regulación del comercio de las mercancías, la forma en que se establecía el orden y supervisión de la división social del 
trabajo en las diferentes áreas (agrícola, manual, minera, comercial, industrial y portuaria).

Igualmente, se necesitaba expandir el comercio y la industria, imponer impuestos, ordenar y regular el uso de la moneda metálica, legitimar los contratos privados de hipotecas, créditos, intereses sobre el capital, mantener algún papel en el mundo de la contratación del "trabajo libre", e impulsar y estimular la ciencia, el arte y la tecnología, para innovar la producción mercantil e industrial; en palabras de Marx (1957):

$\mathrm{Al}$ adquirir nuevas fuerzas productivas, los hombres cambian de modo de producción, y al cambiar el modo de producción, la manera de ganarse la vida, cambian todas sus relaciones sociales [...] Los hombres al establecer las relaciones sociales con arreglo al desarrollo de su producción material, crean también los principios, las ideas y las categorías conforme a sus relaciones. Por tanto esas ideas, estas categorías, son tan poco eternas como las relaciones a las que sirven de expresión. Son productos históricos y transitorios (Marx, 1957:102 y 103).

De tal manera, el papel del Estado se torna crucial en tanto busca lidiar con las propias transformaciones de la explotación del trabajo, de las formas de organizar la producción y proteger la propiedad privada capitalista; tal y como señala Engels (1976), esta figura aparece cuando la sociedad se ha "enredado" en sus propios conflictos de clases, en el momento cuando se demanda una institucionalidad "intermediadora" de esa dialéctica de contradicciones.

Por su parte, esta institución paulatinamente fue tratando de acoger en su seno algunas de las demandas proletarias y darles el tratamiento que pudiera articularse a los intereses que representaba; por ello es que surgen instancias como los ministerios, departamentos y divisiones de trabajo, así como de asuntos sociales que se circunscribían a regular las normas de explotación que el capitalismo y el conservadurismo burgués habían instaurado; relacionado a este particular, se muestra necesario recordar, según Marx (1976): "El derecho al trabajo es, en el sentido burgués, un contrasentido, un mezquino deseo piadoso, pero detrás del derecho al trabajo está el poder sobre el capital, y detrás del poder sobre el capital la apropiación de los medios de producción, su sumisión a la clase obrera asociada [...]".
La necesaria y requerida intervención en las secuelas de la explotación, propiciadas por el "trabajo liberado" y desmontado de los medios de producción fueron exigiendo de forma contundente la apropiación de las experiencias de "atención en lo social", fueran esas de carácter filantrópico, religioso, laico, gremial, civil o de otra herencia.

Dichas protoformas fueron revertidas, moldeadas, condicionadas, legitimadas y reguladas con el fin de adscribirlas a las fuerzas que se aglutinaron como dominantes en este contexto; la burguesía, las iglesias y el Estado (saturadas de patriarcado y conservadurismo) pasan a racionalizarlas bajo un sentido socio-histórico nunca conocido; por tanto, las resquebrajan de su anterior significado para "enfibrarlas" en las contradicciones que se gestaban entre las clases sociales y de esa manera direccionarlas a legitimar tendencialmente el nuevo orden alcanzado.

Una representación de ello es la propuesta Constitucional de 1848, la cual incorporó el droit à l' assitance (derecho a la asistencia) (Marx, 1976) que iba forjando lugar a las necesarias formas de legitimidad de los cambios políticos que la burguesía y la aristocracia financiera estaban moldeando a mediados del siglo XIX.

En síntesis, la figura del Estado va a ser definitiva en el contexto galo, pues se instrumentaliza para dar legitimidad al nuevo "establishment" promulgado por los conservadores, innovando su significado más amplio en la sociedad y en las relaciones de clases capitalistas.

El Príncipe como refería Maquiavelo (2001) a esta creación humana, se coloca como una pieza central del ordenamiento provocado en estos siglos; es una institución que juega un papel diferenciado en una novata sociedad con inéditas tensiones de clases.

El patrón estatal que se edifica en Francia, y luego irradia y trasluce en occidente, marca un conjunto de pautas relevantes entre las demandas sociales y las formas en que se texturiza la vida cotidiana y las posibilidades de reproducción.

El Estado debía constituirse en garante de una base política que abrió el cerrojo de libertad e igualdad prometido virtualmente por la burguesía, pero también dar signos de materialidad de 
una emancipación social, que fue y ha sido cada vez más imposible de alcanzar en dicho ordenamiento humano.

Las conquistas de racionalización que se penetraron en el Estado moderno le facultaron en su momento, para provocar la imagen de una instancia resolutiva y guiadora de la humanidad; sin embargo, también fecundaron en su seno las mismas luchas y confrontaciones que se localizan en cualquier ámbito de la sociedad moderna; por ello, la forma en que la clase hegemónica conduce al Estado, es para el campo del Trabajo Social un referente inesquivable en el estudio de la vida social y de su sentido más amplio en ella.

El Trabajo Social, con sus singularidades, encuentra en las dialécticas de clases y en el Estado moderno, un basamento que le aprovisionó de medios para su constitución, reconocimiento, legitimidad, racionalización, empleabilidad y significado en las relaciones sociales que se profundizaron con el paso de las décadas del siglo XIX y XX en occidente.

Aunado a ello se encuentra la administración pública, la cual proporcionó los andamiajes requeridos por la política de Estado y de gobierno y con ello el estatuto indispensable para la emergencia de diversos servicios sociales, los cuales se definieron como espacios determinantes para dilucidar con más precisión el valor de uso que esta profesión adquiriría.

Cabe subrayar que el Trabajo Social se eslabonaría por tanto con la base estructural de la emancipación alcanzada por esta gesta revolucionaria; igualmente, se concatenaría con las plataformas de la economía política y por ello con el modo de producción instituido; por tanto, sus nexos gravitarían en varias coordenadas, aunque fenoménica y positivistamente tiende a ser reducido y fragmentado a "lo social" (generalmente mentado como algo problemático para su intervención), condición que opaca el cúmulo de articulaciones que le instituyen con la matriz de este nuevo horizonte al que llegó la humanidad.

Estos complejos señalados le dan a esta categoría las posibilidades para materializar formas de atención social derivadas de las prefiguraciones antes señaladas, como a su vez, ir facilitando un carácter tecnificado y profesionalizado -con creación de nichos de contratación, remuneración y respaldo- en tanto maniobraba y se le exigía atenuar, contener, repeler, desfragmentar y reconducir las "exacciones" latentes de las camadas más expoliadas.

\section{Las orientaciones educativas en la Francia posrevolucionaria}

A partir de Iamamoto (2004), es posible evidenciar que las transformaciones del Estado moderno también llevaron a que éste asumiera la dimensión política del conocimiento de una manera distinta a la tradicional en esas décadas.

Igualmente, la vanguardia francesa en el campo intelectual, artístico y de conocimiento en Europa se destacó como un elemento relevante que permite testear a su vez, las transformaciones más amplias acontecidas en el período en estudio; de tal manera:

Francia conservaba la primacía intelectual y artística. Su lengua, literatura, artes y modales se contaban todavía entre los elementos esenciales del cosmopolitismo de la aristocracia europea. [...] En el terreno del pensamiento encontramos la misma variedad. El racionalismo conservaba en él su lugar y el progreso de la ciencias continuaba [...] su divulgación aumentaba de día en día [...] (Lefebvre, 1960: 23).

Europa evidenció un afrancesamiento muy particular durante el siglo XIX, especialmente por las invasiones y avasallamientos que padecieron varias naciones conquistadas por Napoleón I, donde la imposición de la lengua fue básicamente brutal; junto a ello se extendió la penetración literaria e ideológica de las ideas revolucionarias (Réau, 1961) y del etnos burgués. Sin embargo:

De 1808 a 1815, las guerras de independencia se sucedieron en España, Rusia y Alemania, haciendo tambalear al Imperio napoleónico que, abatido por primera vez en la primavera de 1814, se derrumbó definitivamente tras un supremo esfuerzo sobre el campo de batalla de Waterloo. En la medida en que se apoyaba sobre la preponderancia política y militar, la hegemonía cultural de Francia fue arrastrada por ese desastre (Réau, 1961:275)

Por otro lado, a lo interno de Francia, las universidades fueron de las instituciones más antiguas que expresaron, de forma tardía y gradual, los cambios en la base intelectual de este contexto. Producto de esas luchas históricas 
y con el debilitamiento de la monarquía, de la aristocracia y la Iglesia, estas casas de enseñanza fueron presionadas para tener un mayor avance de la ciencia, el arte, la literatura, la política y la economía mercantil.

Ante los límites que reflejaron las universidades, la misma sociedad habilitó otros espacios para poder acrecentar el estudio, la discusión y la investigación de las cuestiones prioritarias de la época, las cuales tenían un fuerte trasfondo de crítica burguesa y liberal, dirigida especialmente al orden monárquico, eclesiástico y feudal de la época que se manifestaba con poco disimulo en las casas de enseñanza superior de París.

Así las cosas, la universidad francesa se va resignificando, aunque no al ritmo que le demandaba la organización política y el modo de producción vigente; ello permite plantear que la enseñanza superior mudaba parcialmente y de manera tardía, al denotar algunas resistencias hacia los impulsos históricos que transforman las relaciones sociales de este período.

Aún avanzada la era revolucionaria, según Ogg (1976), una cantidad no despreciable de universidades seguían manteniendo cierto resabio medieval en su estructura, lo cual llevó a perder aún más la parcial relevancia en su papel de dirección cultural europea; puede suponerse que la sociedad del viejo continente, marcaba un ritmo más acelerado, que el que se gestaba en los claustros.

A pesar de ello, el campo universitario le impuso resistencias a los alcances de la burguesía, en tanto esta clase no tenía mayor maniobra en el campo académico, y, aunque criticada, la estructura del Antiguo Régimen bajo la rectoría de sectores muy vinculados al clero, la aristocracia y la nobleza no era de sencilla sustitución tal y como se redacta a continuación:

Tras el cierre de las antiguas universidades en los primeros años de 1790, la educación superior se había rezagado gravemente, a despecho de los esfuerzos de los revolucionarios para construir una nueva red que remplazase a la del Antiguo Régimen. La reapertura de las escuelas de medicina en París, Estrasburgo y Montpellier, del Museo de Historia Natural, de la Escuela Central de Obras Públicas (rebautizada en 1795 como EcolePolytechnique), del Observatorio, de las Escuelas Normales para la instrucción de maestros y de las demás fundaciones especiales, culminando en el Instituto Nacional de Artes y Ciencias, no remplazó plenamente a las universidades, las academias nacionales y provinciales, los centros eruditos y científicos dotados oficialmente de la anterior monarquía (Ford, 1973: 194).

Lo anterior se puede deber, siguiendo a Gramsci (1999), por la relación distintiva entre los intelectuales y el mundo de la producción, que no es inmediata, como ocurre con los grupos sociales fundamentales, sino que está mediada, en grados diversos, por todo el tejido social, por el complejo de las tensiones hegemónicas y las exigencias históricas que la sociedad le coloca a las universidades.

De tal manera, la figura de la universidad tuvo permutas parciales al inicio de la sociedad burguesa, e incluso, se perfilan necesidades de impulsar prioridades de "formación para el empleo"; aquellos rasgos más "intelectualistas" o "culturalistas", que tomó en cierto momento del Renacimiento y la Ilustración, empiezan a tener cuestionamientos sobre su valor de uso en las relaciones de mercado y legitimación de la sociedad posrevolucionaria.

Según Ford (1973), el conjunto de cambios sociales paulatinamente tomó forma en el mundo académico; una prueba de ello fue la fundación en 1806 de un órgano llamado la Universidad Imperial, que básicamente reflejaba la función y estructura de un ministerio de educación superior que ordenaba la enseñanza en Francia y en las naciones invadidas por Napoleón I (en dicho año en Italia, Suiza y los Países Bajos); en ese radio geográfico se fundan 13 facultades de Derecho, 15 de Ciencias, 7 de Medicina, 10 de Teología Católica y 3 de Teología Protestante.

Sobre ese contexto de la educación superior, Tünnermann (1983) afirma que la Universidad Imperial de corte no fue más que un conjunto de escuelas profesionales eminentemente utilitarista, carentes de núcleo, y colocadas bajo la tutela de un nuevo Estado.

Por ejemplo, el desarrollo del derecho civil francés, según Rudé (1974), derivó en reformas educativas; de ahí se plantea la formación de jóvenes varones para el servicio del Estado, donde se declara que a la población pobre había que proporcionarle la instrucción mínima necesaria para las tareas de empleados, artesanos y 
trabajadores en las distintas nuevas áreas que el comercio, la producción y el mercado demandaban. Lo anterior se secunda a continuación:

Este proceso de transformación socio-económica iba inevitablemente acompañado de cambios esenciales en la cultura y el comportamiento popular, de los que la secularización y la mayor alfabetización son sólo algunas muestras. [...] La educación tenía más valor práctico en una sociedad industrializada, más comercial y en la que la administración era más importante. Para las élites, que tomaban las decisiones cruciales respecto a la inversión en colegios, prometía ser un instrumento muy eficaz para civilizar a las masas y salvaguardar su propio poder (Price, 1998:114).

Sumado a ello, se promulgaron leyes con el propósito de fortalecer la estructura social, en tanto que colocaron la enseñanza privada gratuita operada parcialmente por la Iglesia, aunque con cierta supervisión estatal (Grenville, 1980).

La demanda por nuevos cuadros educativos en la época condujo a la aparición de la llamada Escuela Politécnica (1795), la cual supuestamente se habilitó para todas las clases -desde luego con la finalidad de crear segmentos de mano de obra calificada para el trabajo en la manufactura y la industria- para tratar de impulsar la formación matemática y física, para avanzar en el desarrollo mercantil.

En síntesis, según lo expuesto, es importante resaltar que las transformaciones políticas francesas fueron el detonante para conducir a una "nueva educación", que se generaría con el impulso del proyecto burgués y en articulación al llamado Estado Moderno que promovió el desarrollo naciente del capitalismo; lo que, junto con el avance de esas relaciones sociales, provocan transformaciones históricas más complejas en las instituciones formadoras.

Una de las interrogantes más relevantes que orbitan en este período de la historia, es lo que acontece con las relaciones sociales en el nuevo orden de clases y las formas políticas y de reproducción de la vida.

Para el caso del Trabajo Social, la concatenación con estos cambios educativos estuvo presente mediante las vías de cuadros técnicos no universitarios, o bien en acciones rudimentarias asociadas a prácticas civiles o confesionales.
Las acciones de titulación o enseñanza formal se localizan básicamente a inicios del siglo XX.

De manera más precisa, se anota:

Los comienzos del servicio social francés se sitúan desde 1900 hasta fines de la Primera Guerra Mundial. El servicio social nace, por un lado, en el movimiento higienista y, por otro, en la corriente filantrópica, de la cual pretende diferenciarse a través de una concepción educativa y un anhelo de mayor justicia social. Así nacerán dos movimientos que coexistieron hasta el año de 1938: las visitadoras enfermeras y las trabajadoras sociales. (...) Las trabajadoras sociales representan la otra rama profesional, que se llamó "lo social puro" para distinguirlo del aspecto social y médico-social. Esta rama se desarrolla más lentamente, y sus orígenes son más diferenciados. Se subdivide en tres corrientes distintas: las residencias sociales [centros de atención social instalados en el corazón de barrios obreros, De Robertis, 2004] el servicio social de tipo familiar y los superintendentes de fábrica (Bouquet, 2007:222-223).

Asociado a ello, Beau (1980) reseña que en un principio las asistentes sociales francesas fueron las esposas de aristócratas que dominaban los patronatos, o burguesas "delegadas del pueblo", esculpiéndose como modelo social a seguir, en especial para las mujeres proletarias.

Algunas otras determinantes que fueron dando posibilidades para ese efecto son las siguientes:

Desarrollo de un feminismo reformista y burgués que reivindicará para las mujeres la creación de y el acceso a profesiones médico-sociales y sociales. La secularización de ideas y prácticas sociales, con la separación de la Iglesia y el Estado. La aparición de las "ciencias humanas". La nacionalización científica de los modos de asistencia y el desarrollo de la técnica. En este contexto, nacen las primeras asistentes sociales, según un modelo que será durante largo tiempo más benévolo que profesional (Bouquet, 2007:222).

Por otra parte, se halla que en 1928 se celebra en París la Primer Conferencia Internacional de Servicio Social que reunió 42 representantes de distintas naciones, estimulando en 1932 la creación de un diploma emitido por el Estado, para legalizar y controlar la formación de asistentes sociales, ratificado luego en 1938, aunque a la vera de las instancias universitarias. Al respecto Bouquet (2007) alega: "En Francia, el trabajo social no es considerado como una disciplina sino como un campo de prácticas; de modo que la enseñanza no está bajo la tutela de la universidad. 
Depende del sector de la enseñanza profesional y es de la competencia del Ministerio de Asuntos Sociales y de Solidaridad".

Con lo evidenciado, se puede entrever que a pesar de ser el contexto francés un determinante para el desenvolvimiento del proyecto moderno burgués capitalista, y que su base universitaria bonapartista venía a ser un referente que se asociaba a cierta direccionalidad de la educación superior y las respuestas a la administración pública, el Trabajo Social no fue asumido en ese avance, sino, que la figura del Estado dejó para sí su formación en un nivel técnico y en el campo de la asistencia social expresamente.

Acá se deja en evidencia que una profesión como esta no es posible de analizar únicamente en razón de la fundación de una primera unidad académica o nicho ocupacional, sin duda relevantes, pero que se alinean en una resultante de una totalidad más densa y dialéctica que no salta a primera vista en los análisis.

\section{Explicaciones intelectuales para el nuevo orden social}

La dislocación social que se atisbaba en este período en estudio, junto con la explotación económica y el sufrimiento de un número nada despreciable de personas que parecía empeorar de año a año, fue un conjunto de parámetros explicativos de la vida burguesa.

Una de las respuestas ante esta asoladora realidad de desigualdad provino de la vertiente socialista, la cual nació después de 1815 producto de la debilidad del movimiento obrero que asumió consigo una notable profusión de doctrinas de liberalización social (Lefebvre, 1960).

Junto con ello aparece la diversa obra de Henri Saint-Simon, la cual tuvo eco en esta trama de la historia moderna al reproducir fundamentalmente un pensamiento industrialista, pero tratando de aminorar la confrontación de clases en virtud de la economía y organización de la nación (Guinzo, 1994).

Una trayectoria similar se encontraba en las ideas de Charles Fourier quien defendía la reorganización de las sociedades industriales y la armonía de las relaciones de trabajo en defensa de la propiedad privada (Estermann, 2001).

En ese marco histórico, igualmente resonaron las propuestas fisiócratas de François Quesnay y Anne Robert Jacques Turgot sintetizadas en su razonamiento de que la reproducción de la economía se gestaba por una tendencia similar a la de la naturaleza, y que debía mantenerse al Estado a la vera de esa evolución (Schawarts, 2006).

Un letrado que resonó sobre la forma de resolver la situación de la sociedad del siglo XIX fue Augusto Comte (quien fuera discípulo de Saint Simon y Maistre); es importante destacar que su legado se constituyó en vértice fundamental del orden burgués y liberal, prueba de lo anterior fue la redacción de su Plan de trabajos científicos necesarios para reorganizar la sociedad (1822), donde argumenta que la Revolución Francesa se había apoderado de los espíritus con una anarquía profunda y cada vez más extendida, donde las máximas revolucionarias eran, efectivamente, excelentes para destruir, pero fueron cegadores para reconstruir.

Otra de las mentes que aporta con relieve en la necesidad de comprender la sociedad francesa de la época, y alumno de Comte, fue Émilie Durkheim, quien en el marco finisecular del siglo XIX, plantea categorías analíticas como la de hecho social, así como un metodologísmo sociologista más refinado (López, 2009).

De tal manera, el atisbo de una nueva sociedad fue emplazando la necesidad de contar con un asidero explicativo que tendencialmente cohonestó los intereses de la otrora clase revolucionaria burguesa, al sumir las demandas de las poblaciones más explotadas en explicaciones sociologistas o morales, así como teñidas de un tinte de socialismo utópico que descansó en la justificación de lo que acontecía en las transformaciones políticas y productivas de la época.

Dichas reorientaciones, demandas y configuraciones analíticas de la época son de significancia para el campo del Trabajo Social; en tanto, por un lado, el asidero teológico (católico y protestante) mantuvo su presencia en lo relacionado a las explicaciones de la "cuestión social"; como, por otro, acogió paulatinamente las bases teóricas y racionales como el positivismo o el socialismo 
utópico, las cuales legitimaban el orden existente y anulaban la continuación de la gesta revolucionaria proletaria.

Esta profesión se enriqueció de estas líneas comprensivas para maniobrar en las demandas interventivas que se le colocaban; y por tanto reprodujo el conservadurismo que en síntesis le ha caracterizado tendencialmente.

Por su parte, si bien el contacto de estos agentes con la universidad es tardío (Esquivel, 2012), el principal perfil de esta institución con el que se va a encontrar el Trabajo Social es el de una entidad que ha sido sometida a las exigencias filosóficas, políticas, económicas, culturales, ideológicas y sociales fragmentarias que se deslindaron de la base burgués y capitalista, y donde estos profesionales buscaron tener cabida, en especial en la rama de las llamadas ciencias humanas, del espíritu, del hombre o sociales que se fueron erigiendo en razón de los patrones analíticos antes señalados.

\section{Conclusiones}

Para el análisis socio-histórico del Trabajo Social, se vuelve imperioso el estudio de las transformaciones más amplias de las condiciones de vida y sus oscilaciones revolucionarias.

La impronta que se localiza en el contexto francés, en los siglos en estudio, se define como una de las bases más imperiosas por abordar, en tanto colige la ruptura con un orden de reproducción humana (feudalismo al capitalismo burgués) y replantea determinantes tan elementales para la sociedad como lo son la reorganización y confrontación de las clases (burguesía y proletariado), la institucionalidad requerida para avanzar en la legitimación de un nuevo orden (Estado con su base constitucional de derechos liberales) y las coordenadas esenciales que acompañarían más adelante las lógicas de la producción y la apropiación del trabajo (trabajo libre y propiedad privada).

Los elementos destacados en el párrafo anterior, remiten a la importancia de las consideraciones dadas en este artículo, en tanto se constituyen en un acervo de conocimientos particulares para ahondar en la aprehensión crítica, totalizante e histórica de la sociedad moderna por parte del Trabajo Social.

El estudio realizado en estas páginas deja constancia a su vez de que la comprensión de esta profesión no es acabable desde las líneas que asocian las argumentaciones explicativas de su naturaleza en la fundación de las primeras unidades de enseñanza y titulación, o bien por medio de la localización empírica de nichos primigenios de empleabilidad.

El Trabajo Social se gesta por la imbricación de profundas mediaciones que se anillan para su aparecimiento en la era moderna; por ello, se exige trascender lo visible y desafiar lo explicado.

En el siglo XXI, se han manifestado alteraciones definitivas en las expresiones que adquieren las relaciones de clases (disueltas como categorías analíticas por muchos intelectuales), los ligámenes del Estado con la sociedad civil (guiados por las coordenadas neoliberales), las estrategias de perpetuación del modo de producción (bajo la lógica del capitalismo financiero especulativo), las tensiones para las explicaciones más amplias de la sociedad (llamadas por los posmodernos "metarelatos") y la reproducción del socio-metabolismo de la humanidad (colocado desde hace décadas bajo la proclama socialismo o barbarie); sin embargo, elucidar el presente es un ejercicio histórico.

\section{Referencias bibliográficas}

Beau, N. (1980). Las asistentes sociales en Francia. En Revista Acción Crítica, (7), julio, 1980, pp. 35-42. Lima, Perú: CELATS.

Bloch, M. (1995). Tipos de estructura social en la vida rural francesa. En Revista Génesis, (20), pp. 16-25. París, Francia.

Bouquet, B. (2007). El Servicio Social francés. En Deslauriers, J. y Hurtubise, Y. (Coord.). (2007). El Trabajo Social internacional. Elementos de comparación. pp. 217-246 Buenos Aires, Argentina: Lumen-Hvmanitas.

De Robertis, C. (2004). Función y profesionalización del Trabajo Social. En Di Carlo, E. (Coord.) (2004). La profesión del Trabajo Social. pp. 53-88. Mar del Plata, 
Argentina: Universidad Nacional de Mar del Plata.

Droz, J. (1974). Europa: restauración y revolución 1815-1848. Madrid, España: Editorial Siglo XXI de España.

Duby, G. y Mandrou, R. (1981). Historia de la civilización francesa. México, Fondo de Cultura Económica.

Durán, J. (2008). El secularismo de Saint Simoniano y la crisis de las sociedades tardomodernas. En Revista Electrónica Nómadas, 19 (3), 2008. Consultado el 12 de agosto del 2011 en http://www.ucm.es/info/ nomadas/19/jfduranvazquez.pdf

Engels, F. (1976). Prólogo. En Marx, Carlos. (1976). El Dieciocho Brumario de Luis Bonaparte. Moscú, URSS: Ediciones Progreso.

Esquivel, F. (2012). Fundación de la primera unidad académica del mundo: su contexto emergente en los Países Bajos (Siglo XIX). En Revista Reflexiones 91 (2), 2012. Pp. 151-162. San José, Costa Rica. Consultado el 20 de octubre del 2012 en http://www. reflexiones.fcs.ucr.ac.cr/images/91_2/11ESQUIVEL.pdf

Estermann, J. (2001). Historia de la Filosofía. Quito, Ecuador: Ediciones Abya-Yala.

Ford, F. (1973). Europa desde 1780 hasta 1830. Madrid, España: Ediciones Aguilar.

Gramsci, A. (1999). Antología. México: Editora Siglo XXI.

Grenville, J. (1980). La Europa remodelada 1848-1878. Madrid, España: Editorial Siglo XXI de España.

Guinzo, A. (1994) Condorcet. Filosofía y Política. En Revista Internacional de Filosofía Política, (4), 1994, pp. 138-171. Consultado el 15 de mayo del 2012 en http://e-spacio.uned. es/fez/eserv.php?pid=bibliuned:filopoli1994-4-12903C45-443C-D9BE-F691A379C3D18242\&dsID=condorcet.pdf

Guy, J. (1997). Pobreza, beneficencia y políticas sociales en Francia (siglo XVIII-comienzos del XX). En Revista Ayer, (27), 1997, pp.189-210. Consultado el 15 de mayo del 2012 en http://www.ahistcon.org/docs/ ayer/ayer25_08.pdf
Hobsbawn, E. (1964). Las Revoluciones burguesas. Europa 1789-1848. Madrid, España: Ediciones Guadarrama.

Iamamoto, M. (2004). Reforma do Estado e Impactos no Serviço Social. En Revista Temporalis, 1(1), julio, 2004, pp. 35-81. Brasilia, Brasil: ABEPSS.

Iamamoto, M. y Carvalho, R. (1984). Relaciones sociales y Trabajo Social. Lima, Perú: CELATS.

Lefebvre, G. (1960). La Revolución Francesa y el imperio (1787-1815). México: Fondo de Cultura Económica.

López, M. (2009). El concepto de Anomia en Durkheim y las aportaciones teóricas posteriores. En Revista IberoforumIV (8), julio-diciembre, 2009, pp. 130-147.

Luckács, G. (2003). Testamento político y otros escritos sobre política y filosofía. Buenos Aires, Argentina: Herramientas.

Manrique, M. (1982).De apóstoles a agentes de cambio. Lima; Peru: CELATS.

Martinelli, M. (1997). Servicio Social: Identidad y Alineación. SãoPaulo,Brasil: Editora Cortez.

Maquiavel, N. (2001). O príncipe. São Paulo, Brasil: Martín Fontes.

Marx, K y Engels, F. (1976) Feuerbach. Oposición entre las concepciones materialistas e idealistas. En Marx, K. y Engels, F. (1976). Obras Escogidas. Pp.11-81. Moscú, URSS. Editorial Progreso.

Marx, K. (1957). Miseria de la Filosofía. Moscú, Rusia: Ediciones en Lenguas Extranjeras.

Marx, K. (1976). El dieciocho Brumario de Luis Bonaparte. En Marx, K. y Engels, F. (1976). Obras Escogidas. Moscú, URSS: Editorial Progreso.

Mommsen, W. (1971). La época del imperialismo. Madrid, España: Editorial Siglo XXI de España.

Monereo, J. (2008).Pensamiento políticojurídico de Durkheim: Solidaridad, Anomia y Democracia. En Revista ReDCE, (9), enero-junio, 2008, pp. 299-373. Consultado el 25 de mayo del 2012 en http://www.ugr.es/ redce/ REDCE9pdf/10JLuisMONEREO.pdf 
Montaño, C. (1995).La Naturaleza del Servicio Social. São Paulo, Brasil: Editora Cortez.

Muglioni, J. (1996). Augusto Comte, en Revista Perspectivas: revista trimestral de educación comparada, XXVI (1), marzo, 1996, pp. 225-237. París, Francia: UNESCO

Netto, J. (1992). Capitalismo Monopolista y Servicio Social. São Paulo, Brasil: Editora Cortez.

Netto, J y Falcão, M. (1987).Cotidiano: conhecimento e crítica.SãoPaulo: Editora Cortez.

Netto, J. y Braz, M. (2006). Economia Política: uma introdução crítica.SãoPaulo: Editora Cortez.

Ogg, D. (1976). La Europa del antiguo régimen. Madrid, España: Editores Siglo XXI.

Petit, J. (1997). Pobreza, beneficencia y políticas sociales en Francia (Siglo XVIII-comienzos del XX). En Revista Ayer(25), 1997, pp.179-210. Salamanca, España: Asociación de Historia Contemporánea.

Price, R. (1998). Historia de Francia. Madrid, España: Cambridge UniversityPress.

Réau, L. (1961). La Europa francesa en el siglo de las luces. México: Unión TipográficaEditorial Hispano Americana.

República Francesa (1791) Constitución Francesa. Recopilada en Revista Historia
Constitucional, (1), 2000. ISSN: 1576-4729.

Madrid, España. Consultado el 28 de mayo del 2012 en http://www.historiaconstitucional.com/index.php/historiaconstitucional/ article/view/115/99

Rudé, G. (1974). La Europa revolucionaria (17831815). Madrid, España: Editora Siglo XXI.

Sánchez, A. (1999). Posmodernidad, postmodernismo y socialismo. En Vega, R. (Comp.) (1999). Marx y el siglo XXI. Una defensa de la historia y del socialismo. Santafé de Bogotá, Colombia: Ediciones Antropos.

Schwartz, P. (Coord.). (2006). Variaciones sobre la historia del pensamiento económico mediterráneo. España: Instituto de Estudios de Cajamar.

Tello, N. (2000). Trabajo Social en algunos países: aportes para su comprensión. México: UNAM.

Torres, J. (1987).Historia del Trabajo Social. Bogotá, Colombia: Editores Plaza y Janes.

Tünnermann, C. (1983). Estudios sobre la teoría de la universidad. San José, Costa Rica: EDUCA.

Wolfgang, J. (1971) La época del imperialismo. Madrid, España: Siglo XXI de España. 
